\title{
Modified Tubularised Incised Plate Urethroplasty (TIPU) with Dorsal Inlay Preputial Skin Graft: An Outcome Evaluation of 21 cases.
}

\author{
${ }^{*}$ Belal MT ${ }^{1}$, Bhuiyun $\mathrm{MHK}^{2}$, Hossain $\mathrm{MS}^{3}$, Chowdhury TA ${ }^{4}$, Morshed MS ${ }^{5}$, Bhuiyan AKMM ${ }^{6}$
}

\begin{abstract}
There are different techniques of hypospadias repair, out of them TIPU is widely practiced and popular procedure. Here a midline incision is made over the urethral plate for widening of urethral lumen and creation of neomeatus. Meatal stenosis may subsequently develop at new meatus and it is the limitation of this procedure. In this study TIPU procedure is modified by applying preputial skin graft on incised urethral plate in dorsal inlay fashion and outcome is evaluated. In this prospective study total 21 patients with distal penile hypospadias underwent repair between 2016 and 2017. TIPU urethroplasty was done as usual along with application of a preputial skin graft on midline incised urethral plate. Tubularization was done over appropriate sized catheter and double layers bilateral Dartos flap was applied to cover the suture line. SPC catheterization was done in every patient.
\end{abstract}

1. *Dr. Md. Towhid Belal, Resident Surgeon, Department of Urology, Dhaka Medical College Hospital, Dhaka and Center for Kidney Diseases \& Urology Hospital, Shyamoli, Dkaka. E-mail: tapon.dr@gmail.com

2. Dr. Mohammad Humayun Kabir Bhuiyun, Department of Urology, Dhaka Medical College Hospital, Dhaka and Center for Kidney Diseases \& Urology Hospital, Shyamoli, Dkaka.

3. Dr. Md. Shamim Hossain, Department of Urology, Dhaka Medical College Hospital, Dhaka and Center for Kidney Diseases \& Urology Hospital, Shyamoli, Dkaka.

4. Dr. Tanvir Ahmed Chowdhury, Department of Urology, Dhaka Medical College Hospital, Dhaka and Center for Kidney Diseases \& Urology Hospital, Shyamoli, Dkaka.

5. Dr. Md. Selim Morshed, Department of Urology, Dhaka Medical College Hospital, Dhaka and Center for Kidney Diseases \& Urology Hospital, Shyamoli, Dkaka.

6. Dr. A K M Musa Bhuiyan Department of Urology, Dhaka Medical College Hospital, Dhaka and Center for Kidney Diseases \& Urology Hospital, Shyamoli, Dkaka.

* For correspondence
On $14^{\text {th }}$ post-operative day urethral catheter was removed and on the same day if patient voids satisfactorily, SPC catheter was also removed. The outcome was evaluated according to the Hypospadias Objective Scoring Evaluation (HOSE) system. 95.23\% of the patients achieved apical neomeatus and 90.47\% of slit like meatal shape. Mild degree chordee and normal caliber urinary flow was in $9.5 \%$ and $95.23 \%$ of the patients respectively. $4.76 \%$ of the patients developed urethrocutaneous fistula. Dorsal inlay preputial skin grafting is a very simple and feasible technique to maximize the outcome of TIPU procedure. However, multicenter and high volume data are needed for its wide application.

Keywords: Tubularised incised plate urethroplasty (TIPU), Hypospadias Objective scoring evaluation (HOSE), Hypospadias

\section{INTRODUCTION}

Tubularised incised plate urethroplasty (TIPU) is very popular reconstructive procedure for distal variety of hypospadias. ${ }^{1}$ Cosmetically and functionally it provides excellent outcome. ${ }^{2}$ For creation of a new meatus at the tip of the glans, it is necessary to incise urethral plate as distal as possible, consequently neomeatus may be stenosed due to fibrosis. ${ }^{3}$ Sometimes, it is difficult to create the position of neomeatus at the tip of the glans. ${ }^{4}$ Thus with grafting midline incision can be extended distally at the tip of the glans that reduce fibrosis and other complications associated with TIPU.

This study evaluated both cosmetic and functional outcome by applying the preputial skin graft on incised urethral plate focusing the simplicity of grafting, more anatomical position of neomeatus and reduction of complications of TIPU, i.e. meatal stenosis.

\section{MATERIALS AND METHODS}

This prospective study is done in department of urology, Dhaka Medical College Hospital and Center for Kidney Diseases \& Urology Hospital, Shyamoli, Dhaka between 2016 and 2017. Total 21 cases are included for this procedure.

\section{Inclusion and exclusion criteria}

Patients with irrespective of age with distal penile hypospadias including coronal, subcoronal and distal 
penile variety and mild to moderate degree of chordee are included for this study.

Those with mid-penile and proximal variety of hypospadias, severe degree of chordee, history of circumcision, failed hypospadias repair and other congenital anomaly of the genitourinary tract are excluded from this study.

\section{Preoperative evaluation}

All patients are evaluated by thorough physical examination and specific investigations to achieve general anesthetic fitness. Urine culture are negative in all cases and no one has any blood dyscrasia.

Table I: Patients characteristics

\begin{tabular}{|c|c|c|}
\hline \multicolumn{2}{|c|}{ Median age (range) in years } & $3.5(1.5-7)$ \\
\hline \multicolumn{2}{|c|}{ Hypospadias variety } & \\
\hline \multicolumn{2}{|c|}{ Coronal } & $3(14.28 \%)$ \\
\hline \multicolumn{2}{|c|}{ Subcoronal } & $6(28.57 \%)$ \\
\hline \multicolumn{2}{|c|}{ Distal penile } & $12(57.14 \%)$ \\
\hline \multicolumn{2}{|l|}{ Chordee } & \\
\hline Mild & $<10^{0}$ & $8(38.09 \%)$ \\
\hline Moderate & $10^{0}-45^{0}$ & $13(61.90 \%)$ \\
\hline
\end{tabular}

Operative technique

Under general anesthesia and in dorsal lithotomy position, a stay suture is taken at the tip of the glans at 12 O'clock position. Urethral plate is isolated using a U-shaped incision around meatus then subcoronal circumferential incision is given deep to the Buck's fascia. Penile skin including dartos are degloved upto the root of the penis without any tourniquet with great care not to injure the urethra. All fibrous tissues are excised and Nesbit's placation, if needed, is done to correct chordee. Then appropriately measured dorsal preputial skin is harvested and preserved in normal saline. A midline incision on urethral plate is made extending from meatus to the tip of the glans $4-5 \mathrm{~mm}$ distal to the margin of urethral plate. The incised plate grafted with harvested skin in a dorsal inlay fashion with 6-0 polyglactin suture by interrupted and quilting manner and at this time a tourniquet is temporarily applied. Then the glans wings are mobilized and urethral plate is tubularised with 6-0 polyglactin suture over an appropriate sized urethral catheter. The suture line is reinforced with double layered preputial dartos flap. Then glanuloplasty, meatoplasty and penile skin coverage is completed. All patient underwent urinary diversion with a SPC catheter. A gentle supportive dressing is applied on penis. On $5^{\text {th }}$ post-operative day dressing is removed and patient is discharged from the hospital. On $14^{\text {th }}$ post-operative day urethral catheter is removed and after satisfactory voiding SPC catheter is removed on the same day.

\section{Outcome assessment}

On $5^{\text {th }}$ and $14^{\text {th }}$ post-operative day, at 1 month, 3 month and 6 month patient is followed up and outcome is assessed.

\section{RESULTS}

The median (range) age of repair is 3.5 (1.5-7) years. The native meatus is coronal in $3(14.28 \%)$, subcoronal in 6 $(28.57 \%)$ and distal penile in $12(57.14 \%)$ of the patients. Mild degree of chordee is in $8(38.09 \%)$ and moderate degree of chordee in $13(61.90 \%)$ of the patients. At six months of repair slit like meatal shape is achieved in 19 $(90.47 \%)$ and meatal location is apical in $20(95.23 \%)$ of the patients. $10(47.61 \%)$ of the patients need Nesbit's plication, among all patients straight penis is achieved in $19(90.47 \%)$ and mild degree chordee in $2(9.5 \%)$ of the patients. Single good caliber urinary stream is in 20 (95.23\%) of the patients with Bell shaped flow curve and mean $\mathrm{Q}^{\max } 16 \mathrm{ml} / \mathrm{secis}$ in $20(95.23 \%)$ of the patients is achieved. One patient develops urethrocutaneous fistula that is repaired successfully after 6 months. Acceptable cosmetic results is achieved in $95.23 \%$ of the patients using HOSE scoring system.

Table II: Outcome as per HOSE system

\begin{tabular}{|l|l|c|c|}
\hline \multicolumn{2}{|l|}{ Objective outcome } & $\begin{array}{c}\text { HOSE } \\
\text { score }\end{array}$ & $\begin{array}{c}\text { No. of } \\
\text { patients (\%) }\end{array}$ \\
\hline Meatal shape & Slit like & 2 & $19(90.47)$ \\
& Circular & 1 & $2(9.5)$ \\
\hline Meatal location & Apical & 4 & $20(95.23)$ \\
& Proximal granular & 3 & $1(4.76)$ \\
& Coronal & 2 & $0(0)$ \\
& Distal penile & 1 & $0(0)$ \\
\hline Chordee & Straight & 4 & $19(90.47)$ \\
& Mild <10 & 3 & $2(9.5)$ \\
& Moderate $10^{0}-45^{0}$ & 2 & $0(0)$ \\
& Severe $>45^{0}$ & 1 & $0(0)$ \\
\hline \multirow{2}{*}{ Urinary stream } & Single good caliber & 2 & $20(95.23)$ \\
& Single poor caliber & 1 & $1(4.76)$ \\
\hline Fistula & No fistula & 4 & $20(95.23 \%)$ \\
& Single coronal & 3 & $0(0)$ \\
& Single proximal & 2 & $1(4.76)$ \\
& Multiple or dehiscence & 1 & $0(0)$ \\
\hline
\end{tabular}




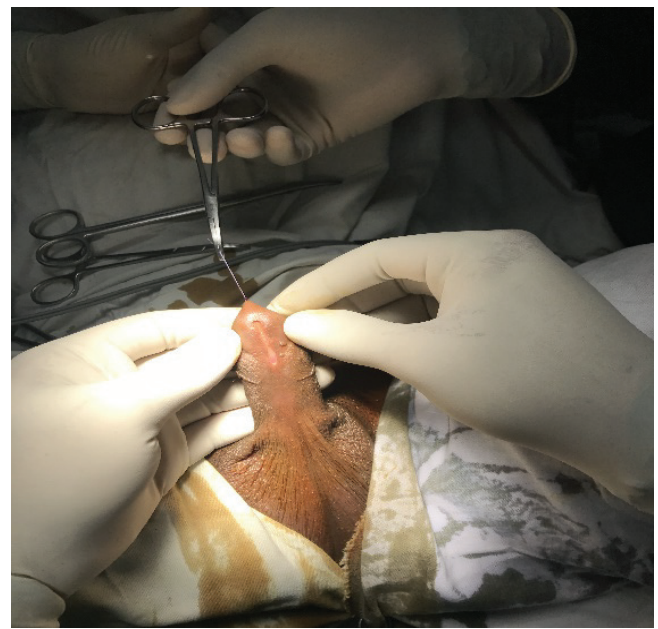

Figure 1: Distal penile variety

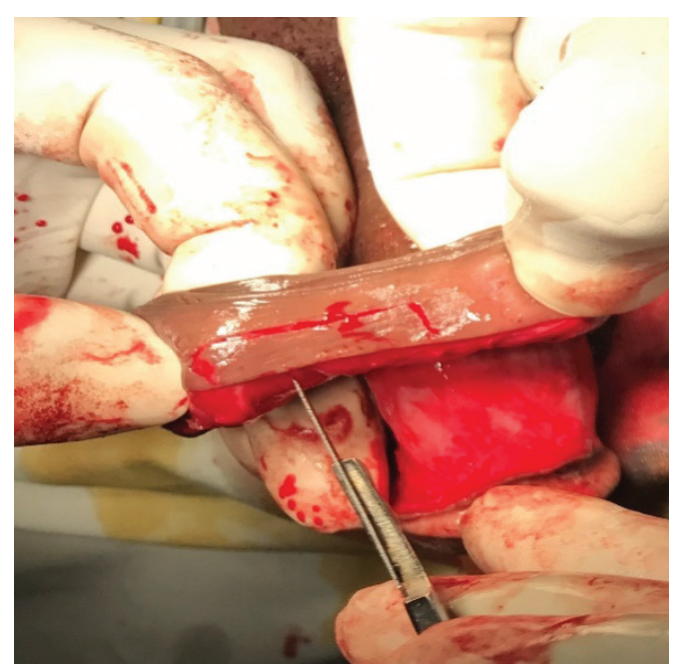

Figure 3: Graft harvesting

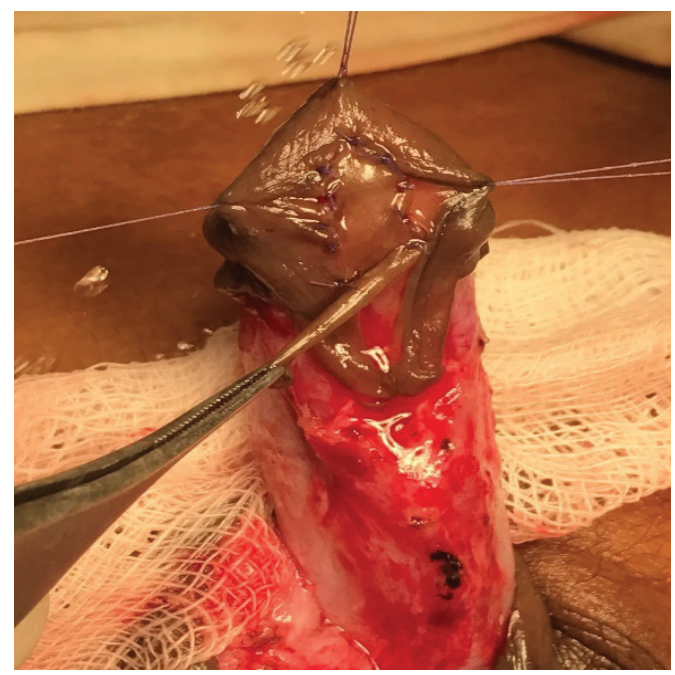

Figure 5: Grafting of urethral plate

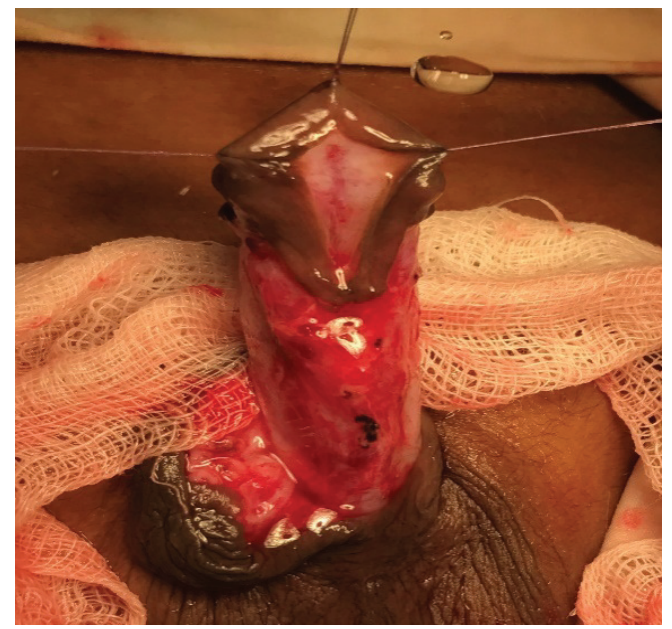

Figure 2: Midline incision of urethral plate

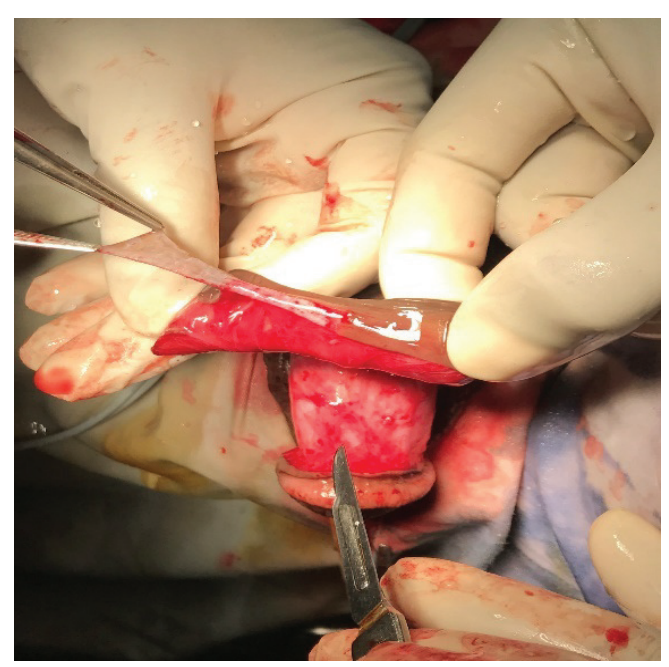

Figure 4: Graft harvesting

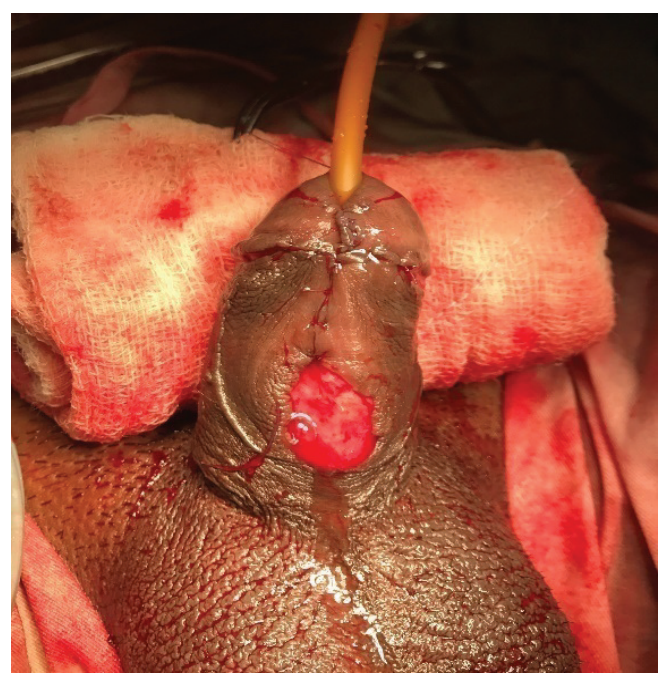

Figure 6: Near completion of procedure 


\section{DISCUSSION}

Hypospadias is a common paediatric congenital disorder. Reported incidence is 1 in 300 new-born males. Among different reconstructive techniques, TIPU procedure that is proposed by Snodgrass in 1994 is most preferred ${ }^{1,2,3}$. This technique carries different complications like meatal stenosis, urethrocutaneous fistula and malposition of meatus ranges from $2 \%$ to $26 \%{ }^{1,4}$. However, neomeatus creation at the tip of the glans and slit-like shape is not possible if midline incision is not extended far enough ${ }^{1,5,6}$. Again, if incision is extended far distally meatal stenosis could be occurred as healing by fibrosis. So, to overcome these problems there are some proposal to modify the original procedure. At first Kolon and Gonzales ${ }^{2}$ in 2000 proposed modification using grafting of incised plate. With grafting urethral plate is immediately covered with epithelium that has several advantages; facilitates tubularisation with adequate width of urethral plate, creation of neomeatus at the tip of the glans as incision adequately extended distally and reduces the rate of meatal stenosis as healing occurs by primary intention due to epithelial covering ${ }^{1,2}$. Similarly, an anatomical apical slit-like meatus creation is possible due to more extension of midline incision as proposed by Jayanthi ${ }^{7}$.

Without grafting the incised urethral plate heals by fibrosis, that may result in the development of urethral strictures and metal stenosis. Similarly, midline incision cannot be extended distally adequately to reconstruct of a meatus at the tip of the glans ${ }^{1,3}$. Grafting immediately covers the incised plate with epithelium and minimises the fibrosis $^{1,2,8,9}$.

Grafting of incised plate was first proposed by Kolon and Gonzales ${ }^{2}$ and in their study with 32 cases they found that development of meatal stenosis, neourethral stricture and urethrocutaneous fistula is significantly lower.

Meatal stenosis and urethral stricture is not observed in this study though midline incision of urethral plate is extended adequately. Thus the experiences suggest that grafting prevent excessive fibrosis of the incised urethral plate as immediately providing an epithelial surface.

Outcome evaluation should be done both in cosmetic and functional aspect. HOSE assessment scoring system designed by Holland et al. ${ }^{10}$ reflect the excellent functional outcome, e.g. a single urinary stream, straight erection, and absence of a fistula and slit-like meatus at the tip of the glans. It is relatively simple to use by clinical observation. A HOSE score of 14 has been recommended as an acceptable outcome. In this study, the HOSE score of $\geqslant 14$ was achieved in $95.23 \%$ of patients.

\section{CONCLUSIONS}

Dorsal preputial skin graft on incised urethral plate in inlay fashion is a straightforward and easy technique. Apical neomeatus can be achieved satisfactorily as well as reducing the incidence of meatal stenosis. Multicenter study and high volume data are needed to compare and for it universal acceptability and efficacy.

\section{REFERENCES}

1. Mouravas V., Filippopoulos A., Sfoungaris D. Urethral plate grafting improves the results of tubularizedincised plate urethroplasty in primary hypospadias. J Pediatr Urol. 2014;10:463-468.

2. Kolon T.F., Gonzales E.T., Jr. The dorsal inlay graft for hypospadias repair. J Urol. 2000;163:1941-1943.

3. Snodgrass W.T. Tubularized, incised plate urethroplasty for distal hypospadias. J Urol. 1994; 151:464-465.

4. Ye W.J., Ping P., Liu Y.D., Li Z., Huang Y.R. Single stage dorsal inlay buccal graft with tubularised incised urethral plate technique for hypospadias reoperations. Asian J Androl. 2008;10:682-686.

5. Erlich R.M. Tubularized-incised urethral plate urethroplasty: is regular dilatation necessary for success? BJU Int. 2000;86:145.

6. Singh R.B., Pavithran N.M. Lessons learnt from Snodgrass tip urethroplasty: a study of 75 cases. PediatrSurg Int. 2004;20:204-206.

7. Jayanthi V.R. The modified Snodgrass hypospadias repair: reducing the risk of fistula and meatal stenosis. J Urol. 2003;170:1603-1605.

8. Hoebeke P., Oosterlinck W. Principles of wound healing as applied to urethra surgery. Ann Urol (Paris) 1993;27:209e12. [in French]

9. Ferro F., Vallasciani S., Borsellino A., Atzori P. Snodgrass urethroplasty: grafting the incised plate -10 years later. J Urol. 2009;182(Suppl.):1730-1734.

10. Holland A.J., Smith G.H., Ross F.I., Cass D.T. HOSE: an objective scoring system for evaluating the results of hypospadias surgery. BJU Int. 2001; $88: 255-258$. 